\title{
O sistema Braille e o ensino da Matemática para pessoas cegas
}

\section{The Braille system and Maths teaching for blind people}

\author{
Lúcia Virginia Mamcasz Viginheski ${ }^{1}$. Antonio Carlos Frasson ${ }^{1}$ • \\ Sani de Carvalho Rutz da Silva ${ }^{1}$. Elsa Midori Shimazaki ${ }^{2}$
}

\begin{abstract}
Resumo: Ao levar em consideração a inclusão de pessoas com deficiência visual no ensino regular, este artigo tem como objetivo centrar-se na perspectiva de referenciar o sistema Braille como um dos recursos de aprendizagem de Matemática para alunos cegos. Caracteriza-se como uma pesquisa exploratória com ênfase bibliográfica, bem como em experiências vivenciadas pela pesquisadora em um Centro de Atendimento Especializado a Pessoas com Deficiência Visual. Foi possível constatar que o sistema Braille se apresenta como um dos recursos disponíveis para o ensino da Matemática, no entanto, ainda são necessárias outras adaptações de materiais que possibilitem, ao aluno cego, o acesso às várias formas de representação dos conteúdos matemáticos.
\end{abstract}

Palavras-chave: Inclusão. Ensino de matemática. Deficiência visual. Cegueira. Alfabeto Braille.

\begin{abstract}
By considering the inclusion of people with visual impairment in regular education, this paper aims to take the perspective of referencing the Braille system as one of the Maths learning resources for blind students. It is characterized as exploratory research with a bibliographic emphasis, as well as describing the experiences of the researcher in a Specialized Treatment Center to People with Visual Impairment. It was possible to verify that the Braille system is presented as one of the available resources for Maths teaching, however, further adaptations in the material are still needed, to enable the blind student to access the several forms of representation in maths.
\end{abstract}

Keywords: Inclusion. Mathematics teaching. Visual impairment. Blindness. Braille alphabet.

\footnotetext{
${ }^{1}$ Programa de Pós-Graduação em Ensino de Ciência e Tecnologia, Universidade Tecnológica Federal do Paraná (UTFPR), Ponta Grossa, PR, Brasil. Rua Maria Marcondes Ribas, 73, Santana, C. P. 362, CEP 85070-696, Guarapuava, PR, Brasil. E-mail: <lmamcaszviginheski@gmail.com>

${ }^{2}$ Departamento de Teoria e Prática da Educação, Programa de Pós-Graduação em Educação, Universidade Estadual de Maringá (UEM), Maringá, PR, Brasil.
} 


\section{Introdução}

Os paradigmas que se apresentam para o século XXI trazem possibilidades de transformações nos processos sociais, educacionais e na forma de produção, desencadeando um contexto de ampla transformação no inter-relacionamento das pessoas e da sociedade.

Ao se conceber o homem como um ser histórico-cultural, cujo desenvolvimento intelectual se dá, sobretudo, por meio de ações interativas, em um mecanismo de apropriação do conhecimento, entende-se que o processo de aquisição da linguagem tem um papel primordial entre os processos de ação e interação no ambiente social/produtivo. Entretanto, as formas de busca por esse conhecimento, que se configuram no processo educacional, calcado, sobretudo, nas premissas do sistema visual e oral, trazem, em seu contexto, preocupações em relação às pessoas cegas, especialmente no que se refere ao processo ensino e aprendizagem e, no caso dessa pesquisa, da Matemática.

O documento "Garantindo o acesso e permanência de todos os alunos na escola" (BRASIL, 2000) relaciona os principais fatos que marcaram a história da Educação Especial, entre eles: a elaboração de uma legislação com deliberações nacionais e internacionais que fortalecem os princípios da Declaração Universal de Direitos Humanos (1948), como a Declaração dos Direitos das Pessoas Deficientes (1975), a Conferência Mundial sobre Educação para Todos (1990), a Declaração de Salamanca (1994), a Lei de Diretrizes e Bases da Educação Nacional (LDBEN) (1996), entre outros. Embora as pessoas com deficiência tenham direito à educação inclusiva garantida pela legislação, muitas das práticas escolares resultam na exclusão por não considerarem as necessidades específicas exigidas pelos diferentes tipos de limitações, no caso deste estudo, a cegueira. Quando se fala em inclusão, refere-se não somente ao acesso e a permanência de tais alunos nas escolas regulares, mas refere-se à apropriação dos conteúdos escolares, que, conforme a experiência de uma das pesquisadoras tem mostrado, muitas vezes, não tem ocorrido nas escolas regulares.

Nesse sentido, pode-se questionar: existe um método que proporcione às pessoas cegas possibilidades de obterem o conhecimento sistematizado além do já institucionalizado? Ou ainda: de que forma um sistema/método pode contribuir para a elaboração de conhecimentos matemáticos para as pessoas cegas? Existem limites nesse recurso? Como as adaptações para alunos cegos podem ser realizadas, para atender às nuanças da disciplina de Matemática? Esses questionamentos centram-se no fato de que, entre as funções atribuídas ao sistema educacional, a principal refere-se à disseminação do conhecimento formal.

Apesar de o Ministério da Educação estabelecer que o ambiente escolar tem como função primordial a aquisição dos conhecimentos e, consequentemente, a sua ampliação, para uma interpretação crítica do mundo e da sociedade, a dificuldade para o acesso ao conhecimento tem se apresentado como um problema para os sujeitos cegos. Eles foram considerados, por muito tempo, como pessoas incapazes de aprender pelo sistema tradicional e, portanto, em situação de desvantagem, "ocupando no imaginário coletivo a posição de alvo de caridade e de assistência social, e não de cidadãos com direitos e deveres" (FRASSON; PIETROCHINSKI; SCHULMEISTER, 2008, p. 182).

$\mathrm{O}$ atendimento educacional prestado às pessoas cegas passou por transformações no decorrer da história, isto é, passou do descaso e da segregação ao atendimento assistencial por meio de instituições sociais ou religiosas, para a atual política de integração em escolas regulares, 
que acompanharam as mudanças ocorridas na Educação Especial, com vistas à inclusão dessas pessoas no ensino regular e na sociedade.

Para Vygotsky (1995), não se pode tratar a cegueira apenas como uma deficiência, mas, em certo ponto, como uma fonte de manifestação de suas capacidades. Segundo ele, outras habilidades sensoriais podem ser desenvolvidas suprindo a falta da visão. Os postulados de Vygotsky (1995) apontam que, para suprir a falta de visão, é preciso compensar e superar a deficiência, o que é possível a partir do momento em que a escola tomar ciência de que todos aprendem, e passe a oferecer condições necessárias para o ingresso, permanência e progresso, na formação acadêmica, a todos que ingressarem no sistema educacional, seja eles deficientes ou não.

O Ministério da Educação, ao propor as Diretrizes Nacionais para a Educação Especial na Educação Básica (BRASIL, 2001), determina que as ações educacionais devem voltar suas atenções a uma educação para todos, respeitando a diversidade, estabelecendo os direitos ao exercício da cidadania, em busca do desenvolvimento de um Estado também para todos:

A construção de uma sociedade inclusiva é um processo de fundamental importância para o desenvolvimento e a manutenção de um Estado democrático. Entende-se por inclusão a garantia, a todos, do acesso contínuo ao espaço comum da vida em sociedade, sociedade essa que deve ser orientada por relações de acolhimento à diversidade humana, de aceitação das diferenças individuais, de esforço coletivo na equiparação de oportunidades de desenvolvimento, com qualidade, em todas as dimensões da vida. Como parte integrante desse processo e contribuição essencial para a determinação de seus rumos, encontra-se a inclusão social. (BRASIL, 2001, p. 22)

Entende-se, portanto, como educação inclusiva aquela que abrange todas as pessoas, independente de suas origens, tanto sociais como culturais, bem como das condições físicas, criando iguais oportunidades de acesso ao conhecimento, ao desenvolvimento, à construção da identidade, enfim, ao exercício da cidadania.

Na educação inclusiva, a diferença, a heterogeneidade, a diversidade são reconhecidas e respeitadas. O acesso e a permanência, com êxito, da pessoa com deficiências no ensino regular é garantido, também, pela sua participação efetiva nas atividades escolares, sendo tal participação uma forma, um parâmetro de avaliação desse processo inclusivo (CAMARGO; NARDI, 2008).

Por atender aos princípios da educação inclusiva, as classes comuns do ensino regular se constituem como espaço privilegiado para a educação das pessoas com necessidades especiais, por ser um espaço onde as pessoas podem interagir com seus pares, aprender com as diferenças (ROCHA; ALMEIDA, 2008). Como afirmam Fernandes e Healy (2010), na formação de uma consciência inclusiva, é necessário conhecer a diversidade, para que se possa aprender com ela.

É importante observar também que, ao se deparar com um aluno cego na sala de aula, faz-se necessário saber que, com relação aos seus direitos e deveres, ele deve ser tratado igualmente como qualquer outro aluno, respeitando-se, no entanto, as características específicas da deficiência bem como seu direito de acesso ao conhecimento sistematizado.

Para se aproximar e se fazer uma incursão nesse universo vivenciado pela pessoa cega, objetiva-se referenciar o sistema Braille como um dos métodos de aprendizagem de Matemática para alunos com deficiência visual, especificamente a cegueira, inclusos no ensino regular. 
A partir de experiências vivenciadas em um Centro de Atendimento Especializado a Pessoas com Deficiência Visual e de informações obtidas mediante levantamentos e revisões bibliográficas, são analisados aspectos relacionados ao código Braille e ao ensino da disciplina. Os limites encontrados foram as formas de realizar adaptações necessárias em situações em que apenas a utilização do sistema Braille se torna um recurso limitado, devido às várias formas de expressão dos conteúdos de Matemática.

\section{O sistema Braille}

Antes de adentrar nos meandros do sistema Braille como um meio auxiliar de integração/inclusão da pessoa cega no contexto social, deve-se ter claro que, na história da humanidade, a pessoa com cegueira era estigmatizada e segregada. Historicamente, as pessoas cegas se depararam com diversos percalços: ora considerados como abençoados, ora como malditos, traziam o estigma de excluídos do convívio social. Exclusão como consequência do processo de caracterização das pessoas interpostas pelo homem.

Goffman (1982, p. 11), ao referir-se sobre os padrões e/ou categorizações em relação às pessoas, destaca:

A sociedade estabelece os meios de categorizar as pessoas e o total de atributos considerados como comuns e naturais para os membros de cada uma dessas categorias. Os ambientes sociais estabelecem as categorias de pessoas que têm probabilidade de serem neles encontradas. As rotinas de relação social em ambientes estabelecidos nos permitem um relacionamento com 'outras pessoas'. Então, quando um estranho nos é apresentado, os primeiros aspectos nos permitem prever a sua categoria e os seus atributos, a sua 'identidade social'.

Neves, Frasson e Cantorani [20--], ao analisarem o processo vivenciado pelas pessoas cegas no contexto da sociedade, trazem à tona que

Os portadores de necessidades especiais, vistos como doentes e incapazes, sempre estiveram em situação ainda mais inferiorizada, ocupando, no imaginário coletivo, a posição de alvos da caridade popular e da assistência social, e não de sujeitos plenos e detentores de direitos sociais, entre os quais se inclui o direito à educação, ao lazer e a atividades motoras. (NEVES; FRASSON; CANTORANI, [20--], p. 1)

No século XIX, em um contexto social de exclusão, Louis Braille, um jovem cego, idealiza um sistema para suprir as necessidades comunicativas dessas pessoas. Assim, em 1825, baseado em um código de comunicação militar desenvolvido por Charles Barbier, oficial do exército francês, criou um sistema composto por um arranjo de seis pontos em relevo, dispostos em duas colunas de três pontos, configurando um retângulo de seis milímetros de altura por, 
aproximadamente, três milímetros de largura, o que revolucionou o sistema de comunicação entre as pessoas cegas, e delas com a sociedade (BIRCH, 1993).

Posteriormente, em 1837, Braille definiu a estrutura básica do sistema, que ainda hoje é utilizada mundialmente em diversos idiomas. $\mathrm{O}$ atual sistema Braille, composto por seis pontos, combinados entre si, num total de 63 possibilidades, permite o acesso ao conhecimento de todas as ciências (BIRCH, 1993). As preocupações com a unificação da simbologia Braille para a Matemática e as ciências iniciaram-se em 1929, em Viena, e, durante todo esse período, foram realizados estudos no mundo todo em busca de um acordo. A partir de 2002, o Brasil faz uso do Código Matemático Unificado para a Língua Portuguesa (BRASIL, 2006a), cujo sistema possibilita - assim como o sistema a tinta - o registro escrito dos conhecimentos científicos matemáticos em todos os níveis de ensino, inclusive, do Ensino Superior.

Braille (18-- apud BIRCH 1993), ao referir-se ao processo de inclusão proporcionado a pessoas cegas, aponta:

O acesso à comunicação, no mais amplo sentido, é acesso ao conhecimento, e este é vitalmente importante para nós não continuarmos sendo menosprezados e dependentes das pessoas que enxergam. Nós não precisamos de piedade nem de ser lembrados que somos vulneráveis. Precisamos ser tratados com igualdade - e a comunicação é a forma de realizar isto. (BRAILLE, 18-- apud BIRCH, 1993, p. 7)

Para Reily (2004), o desenvolvimento do sistema Braille ocorreu na mesma época em que se modificavam as concepções sobre a aprendizagem humana, uma vez que se passa a questionar o fato de se conceber a pessoa com deficiência como inválida, incapaz ou, ainda, associando sua deficiência a um castigo divino.

Neves, Frasson e Cantorani [20--] destacam que:

A teoria e a prática dominantes no atendimento às necessidades educacionais especiais de crianças, jovens e adultos, defendiam a organização de escolas e de classes especiais, separando essa população dos demais alunos. Nem sempre, mas em muitos casos, a escola especial desenvolviase em regime residencial e, conseqüentemente, a criança, o adolescente e o jovem eram afastados da família e da sociedade. Esse procedimento conduzia, invariavelmente, a um aumento do preconceito já tão evidente. (NEVES; FRASSON; CANTORANI, [20--], p. 2)

A partir do desenvolvimento de um sistema de leitura e escrita próprio, as pessoas cegas tiveram o acesso à comunicação escrita, representando um grande passo na luta por seus direitos, pela igualdade de condições, pela independência e autonomia e pelo exercício da cidadania.

Reily (2004) aponta alguns mitos acerca do uso do Braille pelos cegos. Entre eles, destaca-se a habilidade inata para a leitura tátil. A pessoa cega desenvolve sua habilidade tátil da mesma forma que outras áreas sensoriais são desenvolvidas na pessoa que enxerga: "é aprendido, mediado e constituído socialmente" (REILY, 2004, p. 149). 
Quando uma pessoa é acometida pela deficiência visual no decorrer de sua vida, isto é, quando a deficiência é adquirida, pode apresentar dificuldades iniciais na transição do sistema a tinta para o sistema tátil, uma vez que sua habilidade tátil ainda não está desenvolvida para tal. Nesse caso, são necessários o entendimento e a compreensão por parte do professor, possibilitando a ela alternativas de comunicação, evitando prejuízos na sua aprendizagem.

Reily (2004, p. 139) destaca a importância de os professores terem conhecimento sobre o sistema Braille, pois "deter noções sobre as especificidades da leitura e escrita em Braille auxilia o educador a perder o receio de se aproximar do aluno com cegueira".

Mesmo que hoje existam outras formas de registro, como, no caso, a utilização da informática em sala de aula, a utilização do Braille é de fundamental importância, pois permite ao cego o acesso à forma como a palavra é escrita, uma vez que, por meio de outros recursos, o acesso se dá pelo canal da audição, não lhe fornecendo detalhes da escrita, como, por exemplo, a ortografia.

Em relação aos conteúdos matemáticos, o código oferece a possibilidade da expressão matemática escrita, da mesma forma como fazem as pessoas sem limitações visuais, necessitando, em algumas situações, de adaptações específicas. Os símbolos em Braille disponíveis permitem o registro escrito de todo e qualquer conteúdo matemático.

A simbologia Braille utilizada na disciplina de Matemática vai sendo ensinada ao aluno cego pelo professor especializado nesse código, na medida em que os conteúdos vão sendo desenvolvidos pelo professor da disciplina. Conforme as Diretrizes Nacionais para a Educação Especial na Educação Básica (BRASIL, 2006b), a Educação Especial perpassa por todos os níveis de ensino, desde a Educação Básica até o Ensino Superior, transversalmente, oferecendo o suporte necessário para a prática educacional inclusiva. Dessa forma, considera-se importante o apoio oferecido pela Educação Especial ao professor do ensino regular, para que ele desenvolva, com o aluno cego, os mesmos conteúdos que desenvolve com os demais alunos, sem causar-lhe prejuízos na aprendizagem.

Mesmo com a oferta desse apoio, muitas vezes, o ensino da Matemática é efetivado somente por meio da oralidade. Quando se trata do aluno cego, apesar de ele desenvolver uma boa memória auditiva, não lhe é possível apreender a enorme quantidade de conceitos e informações que são trabalhados na escola. Há, portanto, necessidade de tomar notas, conferir se as suas anotações são compatíveis com os apontamentos do professor na lousa (REILY, 2004), o que é permitido pelo sistema Braille.

Cabe salientar que é necessário respeitar as preferências pessoais da pessoa cega. Torres, Mazzoni e Melo (2007) consideram que a preferência pelo uso do Braille está condicionada à habilidade tátil da pessoa. Uma pessoa que foi alfabetizada em Braille pode se sentir mais à vontade na atividade da leitura que uma pessoa que aprendeu o sistema na fase adulta.

Observam-se, no entanto, algumas limitações quanto à utilização do Braille em algumas formas de apresentação de aspectos da Matemática, como, por exemplo, para informações demonstradas por meio de gráficos e tabelas, objetos tridimensionais. Também, ao contrário da leitura visual, que nos permite a leitura do todo, a leitura do sistema Braille é mais lenta, uma vez que, tatilmente, a pessoa cega necessita decodificar letra por letra para formar uma palavra; palavra por palavra até a frase e, muitas vezes, ao final, necessita retornar para entender o contexto.

Dessa forma, alguns cuidados podem ser tomados com relação à produção de textos em Braille, evitando a exaustão no momento da leitura, como: utilizar uma linguagem acessível, 
suprimir palavras e frases desnecessárias. Para o ensino da Matemática, deve haver algumas adaptações.

\section{Algumas adaptações que podem ser associadas ao uso do Braille para o ensino de Matemática}

O sistema Braille possibilita às pessoas cegas o acesso à informação e à comunicação escrita nas mais diferentes áreas do conhecimento, entre elas, a Matemática.

Ao proporcionar ao aluno, com cegueira, diferentes formas de acesso ao conteúdo escolar, por meio do veículo que lhe permite significar o mundo, seja ele tátil, auditivo ou outro, respeitando o tempo necessário para tal, criam-se condições favoráveis à sua aprendizagem, proporcionando-lhe igualdade de condições em relação aos outros alunos (REILY, 2004).

Pacheco, Shimazaki e Mamcasz (1998) desenvolveram um projeto com uma aluna cega que frequentava o Ensino Médio no ensino regular. A pesquisa teve como principal objetivo a busca por alternativas para a elaboração de conceitos matemáticos, relacionados a situações cotidianas da aluna. Foram desenvolvidos os conceitos de área, a partir da exploração do quarto da aluna: o quadrado da soma, um dos produtos notáveis. Para explorar esse conteúdo, fizeram uso de placas de madeira retangulares e quadrangulares, com faces graduadas e não graduadas. Nos resultados, foi possível constatar a consolidação de alguns conceitos, como: a multiplicação como soma de parcelas, a noção de área como medida e a articulação com a propriedade comutativa da adição e da multiplicação.

Fernandes e Healy (2010) desenvolveram um projeto com alunos cegos, a partir de pesquisas realizadas com pessoas sem limitação visual, com o objetivo de elaborar materiais que lhes permitissem a exploração tátil de figuras geométricas, a construção de conceitos de área, perímetro e volume. Fizeram uso de um material adaptado em relevo, constituído por placas de madeira e formas geométricas em EVA, com diferentes relevos. Também possibilitaram, aos alunos cegos, o uso de diferentes instrumentos adaptados para medida.

O desenvolvimento dos projetos citados demonstra que é possível a pessoa cega desenvolver conceitos matemáticos como qualquer outra, sendo necessário, portanto, que o professor conheça e entenda as particularidades da deficiência visual envolvidas no processo, entre elas, a necessidade de adaptações.

Entre os conteúdos matemáticos, alguns relacionados à geometria, tratamento da informação e funções dependem, além do sistema Braille, de outras adaptações para o ensino às pessoas cegas.

Os gráficos e tabelas se constituem por meio de uma organização visual/espacial de dados; assim a pessoa cega pode apresentar dificuldades para esboçá-los se não for orientado pelo professor ou por colegas e se não fizer uso de materiais táteis adequados. Nem por isso o professor deverá deixar de utilizar essas representações, uma vez que elas podem estar presentes em outras situações vivenciadas pela pessoa cega fora do contexto escolar, que poderão ser relacionadas com as experiências vivenciadas na escola.

Além de atuar como mediador nessa construção, o professor pode utilizar outros recursos que possibilitem, ao aluno cego, o acesso a essa forma de informação. Existem, no mercado, muitos materiais que podem ser utilizados com a finalidade de representar os gráficos 
e tabelas com relevo e diferentes texturas. Entre eles, podem-se citar os destacados por Reily (2004) para a transformação de traços em relevos. Pode-se acrescentar, na lista, o papel vegetal:

- desenho em giz de cera sobre a própria figura, tendo como base uma prancha de aglomerado de madeira dura na qual se tenha colado tela de náilon; isso resulta em traços leves que podem ser sentidos pelo cego;

- pintura linear em tinta "puff", que, quando aquecida (com secador de cabelo, por exemplo), cria um volume fofo sobre o traço;

- bolinhas de plastilina (massinha) para fazer pontos de referência sobre a mesa do aluno;

- manipulação das formas essenciais da figura recortadas em EVA (material emborrachado) ou em papelão;

- marcas com thermo-pen, um instrumento aquecido que, aplicado a flexi-paper, produz relevo;

- pintura com tintas texturadas em graus que vão de fino a grosso, variando entre as arenosas, as aveludadas, as craquelentas;

- colagem de cordonê ou barbante sobre o contorno da figura;

- linhas produzidas em thermo-form, para transformar gráficos e figuras em relevo (esse procedimento exige acesso ao equipamento especial);

- reproduções pela técnica clássica de pontilhado linear (REILY, 2004, p. 38).

Um recurso que também pode ser utilizado no ensino de Matemática para cegos é a adaptação por meio da descrição. Como exemplo, pode-se citar uma questão de vestibular, que foi adaptada para pessoas cegas, na Figura 1.

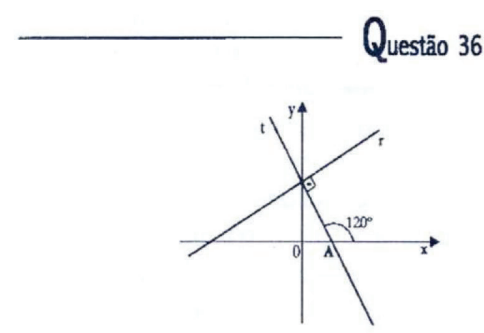

Na figura acima, as retas $r$ e $t$ são perpendiculares e $A=(2,0)$.

As equaçōes da reta $r$ e da reta que é paralela a $t$ e passa pela

origem são, respectivamente, iguais a

A) $3 x-\sqrt{3} y+\sqrt{3}=0$ e $y=\sqrt{3} x$

B) $\sqrt{3} x-3 y+6 \sqrt{3}=0$ e $y=-\sqrt{3} x$

C) $\sqrt{3} x-3 y-6 \sqrt{3}=0$ e $\sqrt{3} y=-x$

D) $3 x-3 y+\sqrt{3}=0$ e $\sqrt{3} y=x$

E) $\sqrt{3} x-3 y+6 \sqrt{3}=0$ e $y=-3 x$

MAT-18
Figura 1. Questão de vestibular Fonte: Viginheski (2004). 
$\mathrm{Na}$ adaptação da prova para pessoas cegas, o gráfico foi substituído pela seguinte descrição em Braille:

Considere o diagrama cartesiano em que as retas $r$ e $t$ são perpendiculares e se interceptam no eixo OY, acima do eixo OX. A reta t corta OX no ponto $A=(2,0)$ e faz ângulo de $120^{\circ}$ com o eixo OX. As equações da reta $\mathrm{r}$ e da reta que é paralela a t e passa pela origem são... (VIGINHESKI, 2004, p. 38).

Essa forma de adaptação tornou a questão bastante complexa e abstrata para a pessoa cega, pois requer dela, além dos conhecimentos sobre Geometria Analítica, a necessidade de construir o gráfico mentalmente apenas com o auxílio de uma descrição realizada a partir de um gráfico visual (VIGINHESKI, 2004). Necessita imaginar a descrição, sem poder esboçar um gráfico, da mesma forma como quem enxerga o faria, e resolver tal questão.

Frente a essa situação, faz-se necessário evitar adaptações complexas, uma vez que as informações contidas na questão são estritamente visuais, deixando a pessoa cega em desvantagem com relação aos vestibulandos sem limitação visual.

O gráfico pode ser adaptado em relevo, conforme a Figura 2.

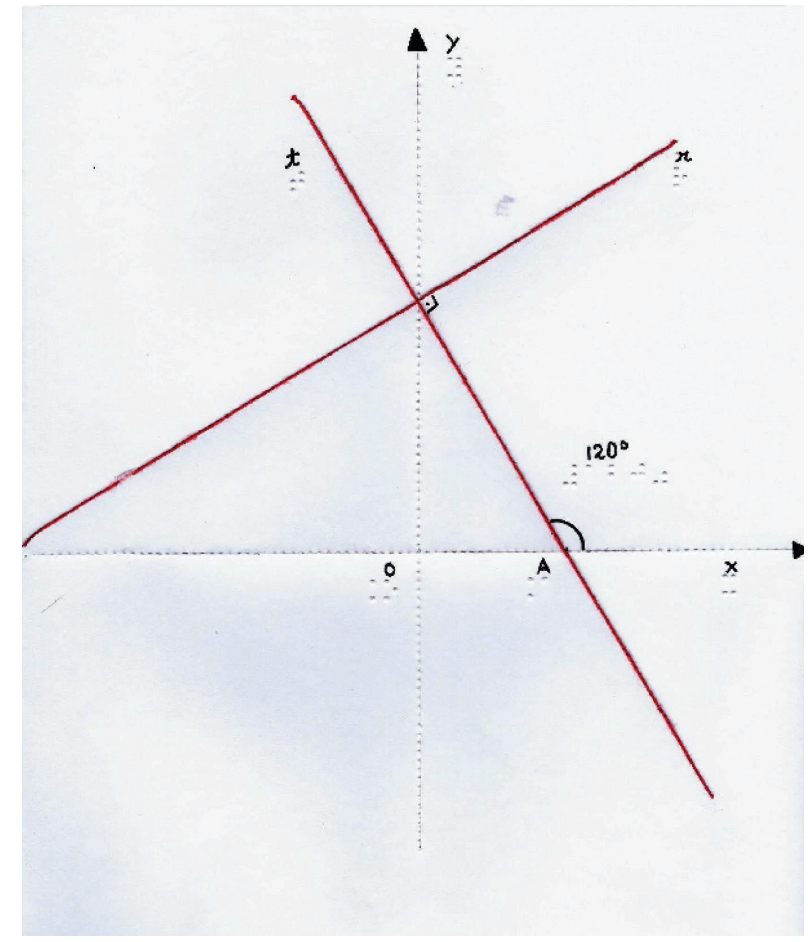

Figura 2. Adaptação em relevo

Fonte: Adaptado de Viginheski (2004). 
O gráfico adaptado desta maneira permite, ao aluno cego, o acesso às informações da mesma forma como o gráfico a tinta. Ressalta-se, portanto, que a adaptação a ser escolhida depende da complexidade existente no que se deseja adaptar. Por isso, é necessário que o professor de Matemática proporcione, ao aluno cego, diferente formas de adaptações, em diferentes situações, para que ele possa se familiarizar, optar pela forma mais adequada à sua condição tátil. Segundo Reily (2004, p. 39):

Antes de realizar a adaptação para o aluno, porém, é importante pensar sobre a figura. Trata-se de uma figura linear, em que os traçados são importantes, ou a figura é constituída por formas fechadas? Essa avaliação implicará uma adaptação por recursos que ressaltem as relações lineares ou as relações entre áreas e formas.

Ao realizar uma adaptação, a pessoa necessita de conhecimento sobre o conteúdo referente à adaptação, sobre a qual precisa fazer uma avaliação apurada para que consiga transmitir todos os detalhes necessários para o entendimento da pessoa cega.

As figuras 3, 4 e 5 apresentam outras formas de adaptações de gráficos e tabelas que podem ser realizadas:

Figura 3. Adaptação de gráfico utilizando EVA com textura

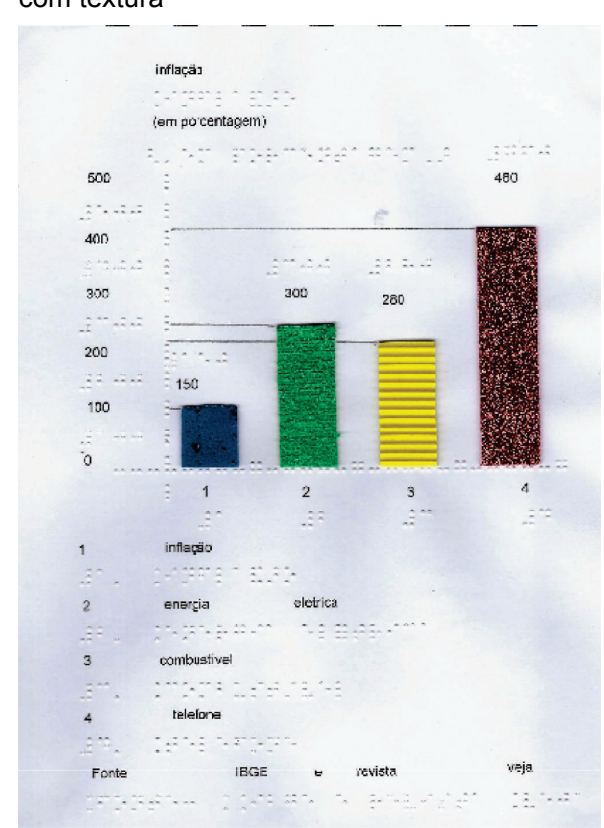

Fonte: adaptado de Giovanni e Bonjorno (2005).
Figura 4. Adaptação de tabela em Braille

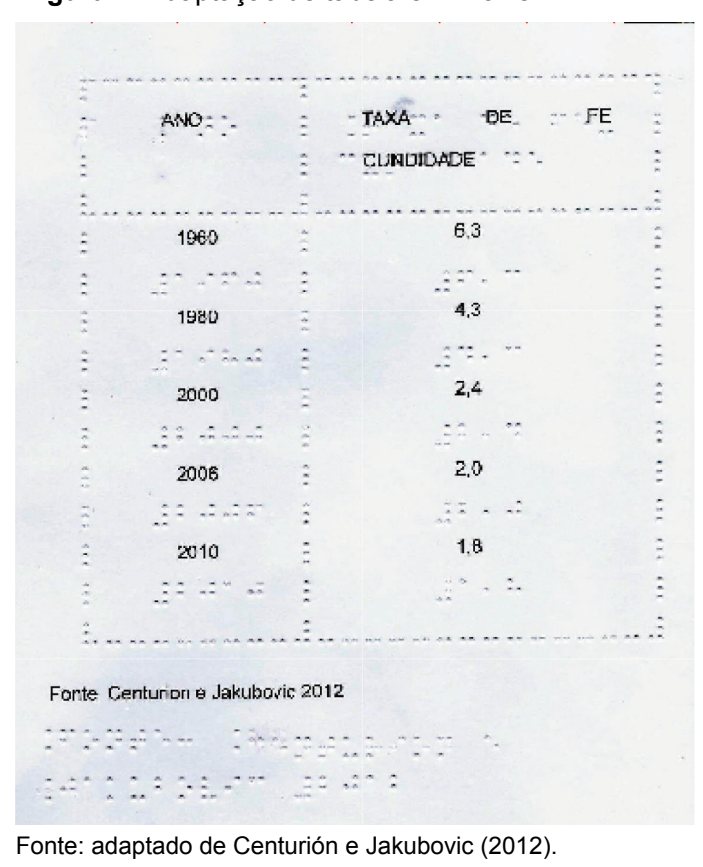




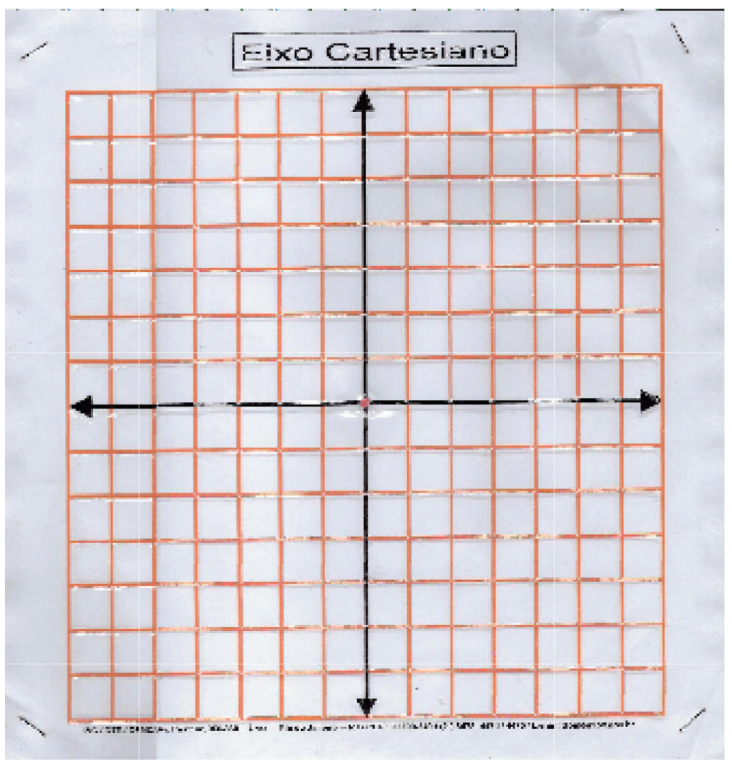

Figura 5. Adaptação de gráfico em termoform

Fonte: Instituto Benjamin Constant (2007).

A adaptação do plano cartesiano nesse material permite, ao aluno cego, a elaboração de vários gráficos, fazendo uso de etiqueta adesiva e barbante.

Observa-se que, em todas as adaptações, faz-se necessária a atuação do professor como mediador, auxiliando o aluno na interpretação das informações, pois se reafirma a questão de a leitura tátil ser diferente da leitura visual, uma vez que as informações são coletadas parte a parte.

Para Reily (2004, p. 39):

Há maneiras de tornar a imagem acessível ao cego, que tem, como todos nós, o direito de ser público (e também produtor, por que não?) da cultura imagética. É preciso realizar uma conversão semiótica, de tal forma que o signo visual seja apreendido por via tátil-verbal. A palavra do outro descreve e significa, e a pessoa com cegueira então se apropria do sentido, trazendo suas experiências pessoais para a situação.

O Ministério da Educação também aponta alguns cuidados na adaptação de conteúdos matemáticos para alunos cegos, como, por exemplo, os objetos tridimensionais. A representação de tais objetos não proporciona tatilmente a mesma percepção que visualmente. É aconselhável a utilização dessas representações com reserva, adicionando, às informações táteis, informações verbais. Com relação às figuras geométricas, considera-se importante levar em conta o tamanho adequado para o reconhecimento tátil e a utilização de objetos com as formas geométricas estudadas, sejam elas planas ou tridimensionais (BRASIL, 2006b). 


\section{Considerações finais}

Há aproximadamente dez anos, a falta de recursos específicos para o ensino de pessoas cegas era considerada uma dificuldade frente à inclusão educacional. Atualmente, existem outros recursos, além do sistema Braille e do soroban, para o ensino de Matemática a pessoas cegas, como: materiais adaptados, jogos, softwares, entre outros. Mesmo que os recursos disponíveis possam apresentar limites para alguns conteúdos na disciplina, percebe-se que as maiores limitações para esses alunos se instalam a partir da prática docente.

O professor, ao fazer uso apenas da oralidade para ensinar Matemática para alunos cegos, ou utilizar recursos adaptados apenas para a demonstração dos conteúdos, pode contribuir para o surgimento de lacunas na aprendizagem dessas pessoas, uma vez que detalhes importantes para a apropriação desses conteúdos não são considerados. Em ambas as situações, o aluno cego é um espectador, não participando ativamente no processo de construção dos conceitos abordados.

O acesso de alunos cegos ao conhecimento matemático científico depende, também, dos procedimentos metodológicos utilizados pelo professor. De nada vale todo o aparato tecnológico existente, se a prática docente ainda é hegemônica, excludente.

A partir do momento em que o professor tem conhecimento das características individuais dos alunos cegos, de suas necessidades, dos recursos existentes para o seu ensino, e buscar estabelecer um bom relacionamento com eles, considerando-os como os demais alunos, estará contribuindo para que, de fato, a inclusão se efetive.

Neste artigo, não se teve a menor pretensão de esgotar o assunto, na medida em que foram sugeridos apenas alguns aspectos relacionados ao ensino da Matemática para alunos com deficiência visual. Quanto a isso, ainda há muitas pesquisas a serem efetivadas a fim de se implementar o atendimento a esses alunos de forma que: eles tenham acesso, permanência nas escolas de ensino regulares; se apropriem dos conteúdos escolares com propriedade, e sejam capazes de utilizá-los em suas práticas sociais. Daí a importância de se dar continuidade às pesquisas desta ordem e, sobretudo, que haja uma maior divulgação delas entre todos aqueles que, de alguma forma, têm interesse e necessidade de conhecer o assunto. Ressalta-se, certamente, sobretudo aqueles que estão envolvidos na inclusão educacional. 


\section{Referências}

BIRCH, B. Louis Braille. São Paulo: Globo, 1993 (Personagens que mudaram o mundo: os grandes humanistas).

BRASIL. Resolução CNE/CEB nº 2, de 11 de setembro de 2001. Institui diretrizes nacionais para a educação especial na educação básica. Diário Oficial da União, Brasília, 14 set. 2001. Seção 1E, p. 39-40. Disponível em: <http://portal.mec.gov.br/cne/arquivos/pdf/CEB0201.pdf>. Acesso em: 25 ago. 2012.

BRASIL. Ministério da Educação. Código matemático unificado para a língua portuguesa. Brasília: Secretaria de Educação Especial, 2006a.

Garantindo o acesso e permanência de todos os alunos na escola: alunos com necessidades educacionais especiais. Brasília: Secretaria de Educação Especial, 2000 (Projeto Escola Viva). Disponível em: <http://www.dominiopublico.gov.br/pesquisa/DetalheObraForm.do?select_ action $=\&$ co_obra $=126056>$. Acesso em: 10 set. 2014.

. Saberes e práticas da inclusão: desenvolvendo competências para o atendimento às necessidades educacionais especiais de alunos cegos e de alunos com baixa visão. 2. ed. Brasília: Secretaria de Educação Especial, 2006b.

CAMARGO, E. P.; NARDI, R. O emprego de linguagens acessíveis para alunos com deficiência visual em aulas de óptica. Revista Brasileira de Educação Especial, Marília, v. 14, n. 3, p. 405-426, set./ dez. 2008.

CENTURIÓN, M.; JAKUBOVIC, J. Matemática: teoria e contexto - $6^{\circ}$ ano. São Paulo: Saraiva, 2012.

FERNANDES, S. H. A. A.; HEALY, L. A inclusão de alunos cegos nas aulas de matemática: explorando área, perímetro e volume. Bolema, Rio Claro, v. 23, n. 37, p. 1111-1135, dez. 2010.

FRASSON, A. C.; PIETROCHINSKI, A. R.; SCHULMEISTER, C. Auditory deficient people: his educative and social inclusion by Norbert Elias. In: SIMPOSIO INTERNACIONAL PROCESO CIVILIZADOR, 11., 2008, Buenos Aires. Anais... Buenos Aires: Universidad de Buenos Aires, 2008. p. 182-191.

GIOVANI, J. R. A conquista da matemática: oitava série. São Paulo: FTD, 2002 (Coleção a conquista da matemática).

GIOVANNI, J. R.; BONJORNO, J. R. Matemática completa. 2. ed. São Paulo: FTD, 2005.

GOFFMAN, E. Estigma: notas sobre a manipulação da identidade deteriorada. 4. ed. São Paulo: Brasiliense, 1982.

INSTITUTO BENJAMIN CONSTANT. Função do $\mathbf{1}^{\mathbf{o}}$ grau ou função afim. Rio de Janeiro: Instituto Benjamin Constant, 2007.

NEVES, G. N.; FRASSON, A. C.; CANTORANI, J. R. Educação física adaptada ao deficiente visual. [S.l.: s.n.], [20--]. Disponível em: <http://www.educadores.diaadia.pr.gov.br/arquivos/ File/2010/artigos_teses/EDUCACAO_FISICA/artigos/Educacao_Fisica_adaptada.pdf > . Acesso em: 15 ago. 2012. 
PACHECO, E. R.; SHIMAZAKI, E. M.; MAMCASZ, L. V. “Área é igual a a.b?”: a formação de conceitos em geometria e álgebra por uma aluna portadora de deficiência visual. In: CONGRESSO IBERO-AMERICANO DE EDUCAÇÃO ESPECIAL 3., 1998, Foz de Iguaçu. Anais... Brasília: Secretaria de Educação Especial, 1998. p. 306-308.

REILY, L. Escola inclusiva: linguagem e mediação. Campinas: Papirus, 2004.

ROCHA, M. M.; ALMEIDA, M. A. Ensino itinerante para deficientes visuais: um estudo exploratório. Revista Brasileira de Educação Especial, Marília, v. 14, n. 2, p. 201-216, maio/ago. 2008.

TORRES, E. F.; MAZZONI, A. A.; MELO, A. G. Nem toda pessoa cega lê em Braille, nem toda pessoa surda se comunica em língua de sinais. Educação e Pesquisa, São Paulo, v. 33, n. 2, p. 369-385, maio/ago. 2007.

VIGINHESKI, L. V. M. Vestibular: o desafio da inclusão na exclusão. Analecta, Guarapuava, v. 5, n. 2, p. 38-42, jul./dez. 2004.

VYGOTSKY, L. S. Fundamentos da defectologia. Havana: Pueblo y Education, 1995. (Obras completas, tomo 5). 